\title{
Research on Fuzzy Control Based Flexible Composite Winding System
}

\author{
He Xiaodong, Shi Yaoyao, and Kang Chao \\ School of Mechanical Engineering, Northwestern Polytechnical University, Xian 710072, China \\ Correspondence should be addressed to Shi Yaoyao; shiyy@nwpu.edu.cn
}

Received 10 November 2015; Revised 18 January 2016; Accepted 19 January 2016

Academic Editor: Ping Feng Pai

Copyright ( $) 2016$ He Xiaodong et al. This is an open access article distributed under the Creative Commons Attribution License, which permits unrestricted use, distribution, and reproduction in any medium, provided the original work is properly cited.

In the process of composite resin prepreg tape winding, the presence of pores or voids among the layers of composite can result in reduced strength of winding. To alleviate this problem, it is required that the composite tape winding machines be designed such that the layers of composite are evenly wound on the previous one. The paper presents a novel design of flexible winding system for composite tape winding. Based on the analysis of errors in winding process, the novel winding system eliminates winding point error and winding angle error based on the speed controlled flexible roller. This paper also presents the kinetic analysis of the novel system and its controller design. Experiments are conducted on the novel winding system. The experimental results illustrate that the novel flexible winding system has a good performance in winding accuracy.

\section{Introduction}

Composites have been widely used in aerospace engineering and other fields for their advantages like high specific strength, high specific modulus, good thermal stability, and good high temperature performance. Tape winding is a major method to manufacture the nozzle of rocket motors [1]. The resin prepreg tape was deposited by a compaction roller during composite winding process $[2,3]$. Littlefield et al. designed a pneumatic compaction roller for composite placement [4]; Rudd et al. used a compaction roller for winding a composites gun tube [5]; Hassan et al. analyzed heat transfer for composite placement with a steel compaction roller [6]; Aized and Shirinzadeh optimized the composite placement process by a robot with a compaction roller [7]. However, during the process, the tape would be deformed by the compaction force [2]. The pores or voids between winding layers are inevitable which will result in poor dispersion of materials and affect the overall performance of the composite component. In order to decrease the pores, Costa et al. showed the influence of the porosity in carbon fiber/epoxy resin and carbon fiber/bismaleimide resin composites on material performance [8]; Madsen and Lilholt built a theoretical model for the effect of pore phenomenon on unidirectional fiber composite performance [9]; Koushyar et al. focused on the phenomenon of carbon fiber/epoxy prepreg growing under hot pressing and vacuum [10].

All the research above shows that there would be winding errors between the original shape of mandrel and the composite layers. In this paper, a novel tape winding system using a flexible roller and a winding speed controller is presented, which would eliminate the winding angle errors and position error of winding point in composite tape winding process. The experiment results demonstrate that the flexible winding system has pretty good quality to eliminate the winding errors.

\section{Composite Tape Winding Process}

The composite tape winding is a kind of filament winding; it consists of several steps like wrapping resin prepreg carbon fiber/glass fiber tape onto the mandrel by the combined action of compaction pressure from the roller, tape tension, and winding temperature, extruding pores from tape-layer interfaces, making the interlayer bonding of prepreg tape tight. The schematic is shown in Figure 1(a) [11]. During the winding process, the resin prepreg tape is wrapped to the winding point on mandrel through a compaction roller, layer by layer at a certain angle called winding angle. 


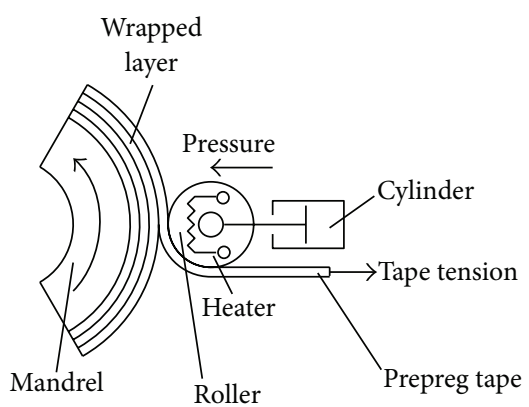

(a)

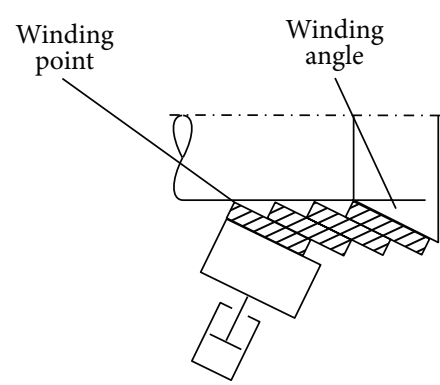

(b)

FIGURE 1: Composite tape winding process.

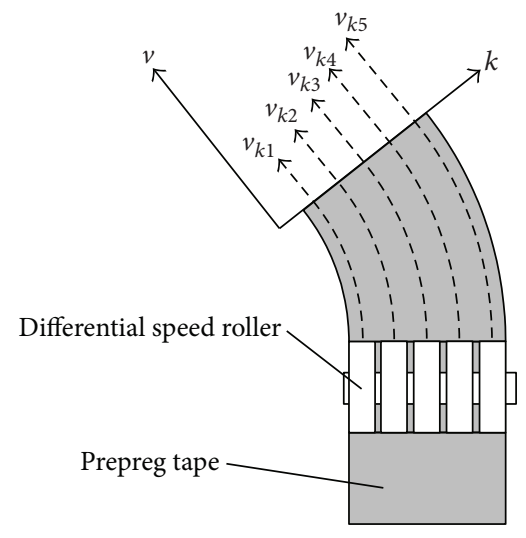

FIGURE 2: Differential speed rollers for nonzero winding angle.

Nonzero winding angle is needed when a nozzle for rocket motor was produced [12], shown in Figure 1(b). In order to avoid the influence by double curvature resulting from winding angle, differential speed rollers have been used to transform the deformable prepreg tape into sector to fit the winding angle, as shown in Figure 2.

The speed distribution for the differential speed rollers at the prepreg tape can be described as

$$
\frac{\mathrm{d} v_{k}}{\mathrm{~d} k}=\frac{\sin \theta}{R} .
$$

Here, $v_{k}$ is velocity of a particular roller, $k$ is the distance between the roller and the winding point, $R$ is the radius of winding mandrel, and $\theta$ is the winding angle.

The compaction roller moves along the mandrel and deposits the resin prepreg tape on the wrapped layer; the winding speed could be calculated by (2); it is obvious that the speed is related to the thickness of the tape. In an ideal winding status, the tape thickness is a constant, while the winding speed of the compaction roller and the increment of wrapped layers can be completely fit, as shown in Figure 1(b). Hence,

$$
B=\frac{\delta}{\sin \theta} \text {. }
$$

Here, $B$ is the winding speed, feed distance per revolution, and $\delta$ is the thickness of the prepreg tape.

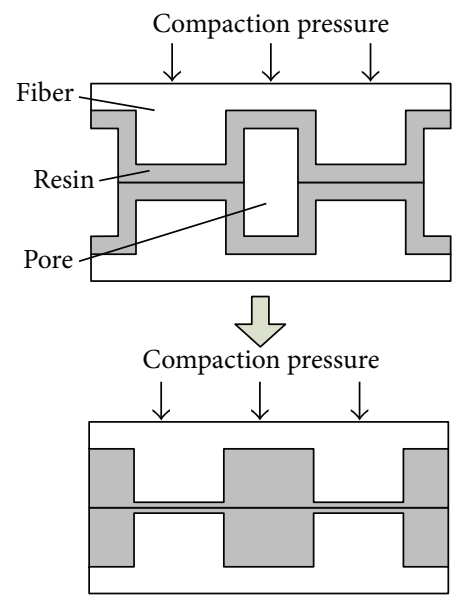

Figure 3: Combination of the prepreg tape.

During the tape winding process, the tape would be combined and the pores between tape layers could be extruded by compaction pressure [13]; the accuracy movement of compaction roller is the precondition to the combination, as shown in Figure 3.

During the practical winding process, the tape thickness can be deformed due to the effects such as compaction force, tensile force, and the transformation by differential speed rollers, and there would be errors in the prepreg process; these phenomena would cause tape thickness error, which leads to errors between the moving compaction roller and the accumulation tape layers. The errors between compaction roller and tape layers would lead to the errors in tape winding.

\section{Winding Errors Analysis and Design Requirements on the Roller System}

According to Figure 1, winding process is related to both accumulation of the resin prepreg tape and movement of the compaction roller. An identical speed of the compaction roller compared to the deposition speed of wrapped tape should be operated during the winding. The error of tape thickness would result in error between the tape layer and 


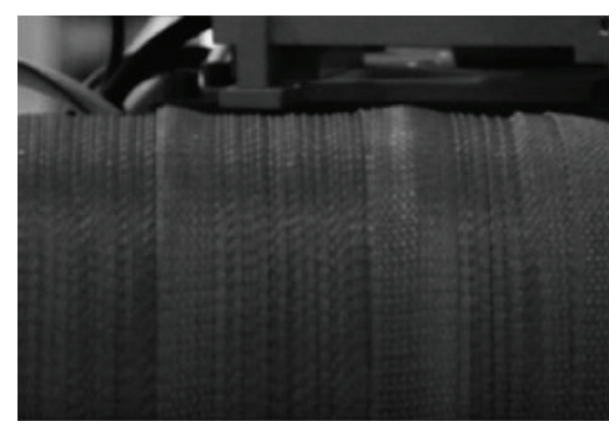

FIGURE 4: Wavy surface on tape winding product.

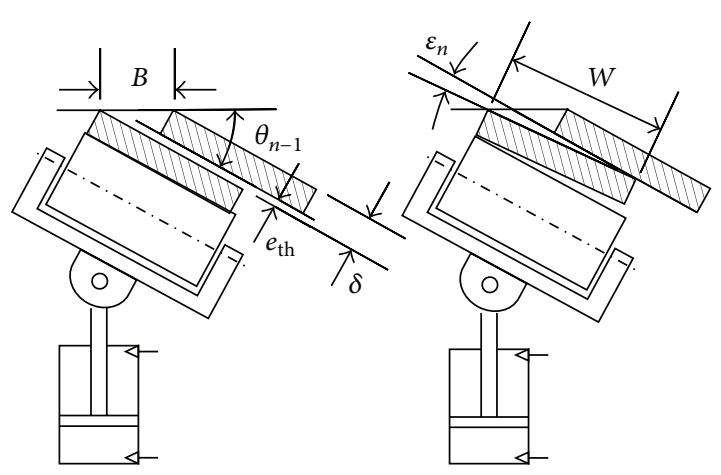

FIGURE 5: Winding angle error in thinner tape.

the moving roller and flaws in the winding product, such as the wavy surface shown in Figure 4.

The flaws in winding product could be analyzed in two situations: thinner tape and thicker tape used in winding process.

As shown in Figure 5, thinner tape used in winding process would be wrapped behind the roller. The winding tape would be located across the wrapped layer, and there would be a pore between winding tape and wrapped layer. Meanwhile, the outer edge of the tape would be shrunken for the tensile force. Finally, the winding angle would be decreased. Hence,

$$
\begin{aligned}
e_{a}(n) & =\theta-\theta_{n}=\sum \varepsilon_{n}, \\
\varepsilon_{n} & =\arcsin \left[\frac{B}{W} \sin \theta_{n-1}-\frac{\delta-e_{\mathrm{th}}}{W}\right] .
\end{aligned}
$$

Here, $W$ is the width of the prepreg tape, $e_{\mathrm{th}}$ is the tape thickness, $\varepsilon_{n}$ is the angle increment between $n$ layer and $n-1$ layer, $\theta_{n}$ is the winding angle at $n$ layer, and $e_{a}$ is the winding angle error at $n$ layer.

The winding angle decrease model is shown as (3) and (4). This is working on a simplification that the tape would not be banded in the section direction. It is shown that the error between the wrapped layers is integral and nonlinear to the thickness error.

It is more complex when the winding tape was thicker than the design. According to the coherence of the interface for wrapped layer, there are two cases, slippage or not.

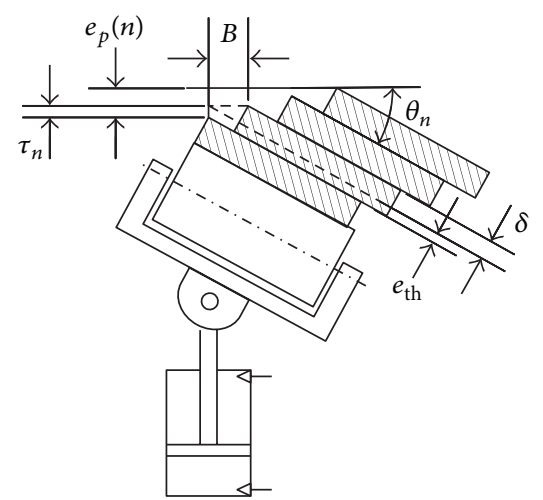

FIgURE 6: Winding position error in thicker tape.

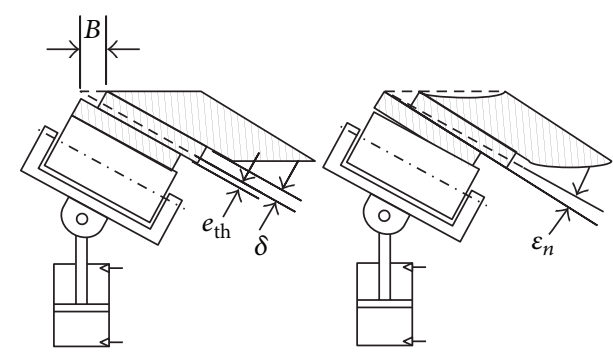

FIGURE 7: Winding angle error in thicker tape.

As shown in Figure 6, the compaction roller would lag to the wrapped layer because the moving roller is slower than the accumulation of tape layers when using thicker tape.

If the tape layer would not be slipped under the compaction, as shown in Figure 6, the laminated tape layer would push the compaction roller over the winding point; therefore, a position error has been produced as

$$
\begin{aligned}
e_{p}(n) & =\sum \tau_{n}, \\
\tau_{n} & =\frac{\delta+e_{\mathrm{th}}}{\cos \theta_{n}}-B \tan \theta_{n} .
\end{aligned}
$$

Here, $e_{p}(n)$ is the winding position error at $n$ layer and $\tau_{n}$ is the winding position increment between $n$ layer and $n-1$ layer.

In this situation, the winding angle would not be changed, and the position error is integral to $e_{\mathrm{th}}$ and $B$.

In another condition, when the compaction force was over the bonding strength, the compaction roller would push the layer slip, and the winding angle would be increased, shown in Figure 7. Hence,

$$
\begin{aligned}
e_{a}(n) & =\theta_{n}-\theta=\sum \varepsilon_{n}, \\
\varepsilon_{n} & =\operatorname{arccot}\left[\frac{W}{\delta+e_{\mathrm{th}}-B \sin \theta_{n-1}}-\cot \theta_{n-1}\right] .
\end{aligned}
$$

The winding angle increase model is shown as (7) and (8), which is working on an assumption that outer edge of the layer would not be reduced. It is shown that the increased angle error has the same features as the decrease model. 


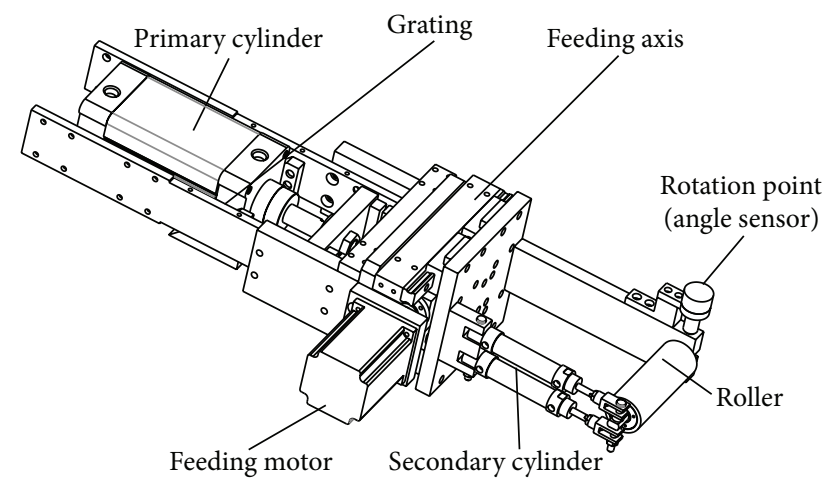

FIgURE 8: Flexible roller system platform.

In all the above, it can be seen that the tape thickness error would lead to winding angle error and position error during winding process. To eliminate these errors, a novel design of flexible tape winding system had been presented including the flexible roller system and the winding speed control system.

In order to acquire the winding angle error and winding position error, the flexible roller system should be able to follow the changing of the winding angle and measure the winding point position. The winding speed control system should control the winding speed to eliminate the winding angle error and the position error caused by the tape thickness error.

\section{A Novel Design of Flexible Roller System}

Based on the analysis of the winding errors, a flexible roller system should be designed to acquire and distinguish the errors. The flexible roller system has been designed in Figure 8.

As shown in Figure 8, a flexible roller with cylinders and sensors is driven by feeding motor on the feeding axis. Double cylinders, the primary one and the secondary one, are adopted in the roller system. The primary cylinder provides compaction force during winding process; linear grating assembled on the main cylinder is used to measure the winding position error. The secondary cylinder pushes the flexible roller yawing around the rotation point; an angle sensor installed on rotation point measures the winding angle in real time.

The principle of flexible roller system is shown in Figure 9. In order to distinguish the errors, the roller should yaw around the winding point on the feeding axis to acquire the winding angle. Three axes are used in the system, which include feeding axis ( $Z$-axis), cylinder axis ( $X$-axis), and rotation axis ( $B$-axis). The flexible roller system comprises the machine coordinate system $\{M\}$, work piece coordinate system $\{W\}$, rotation system $\{B\}$, and roller system $\{R\}$. During the winding process, when winding angle changes, the flexible roller would yaw around the rotation point, and there would be an error on the winding point between roller and tape layer. In order to adjust the error, the system calculates interpolate values based on the structure of roller system

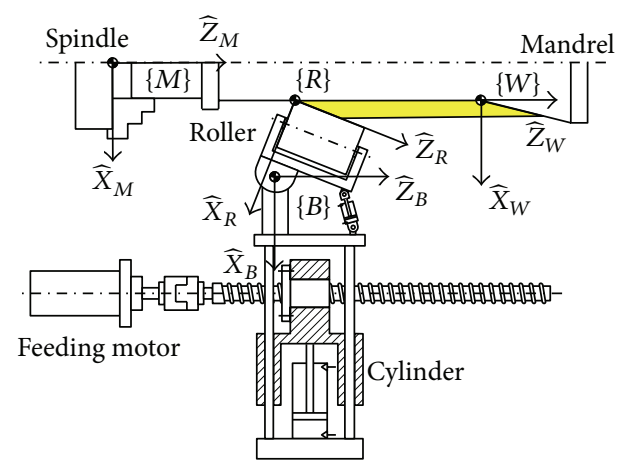

Figure 9: Principle of flexible roller system.

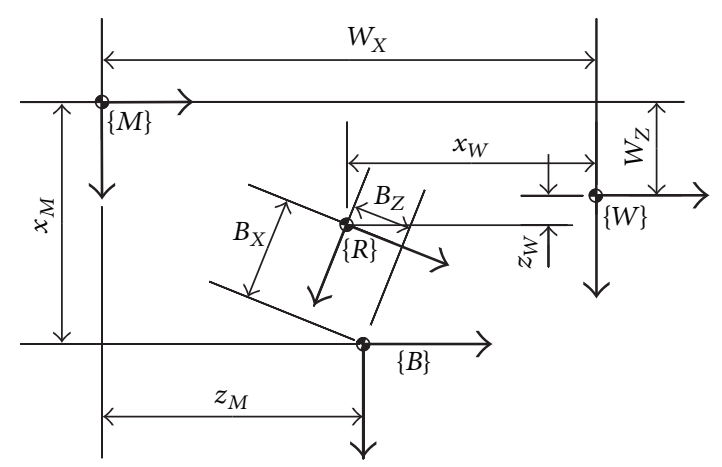

Figure 10: Basic structure of flexible roller system.

and the yaw angle increment of $B$-axis; with the values, an interpolate controller adjusts the speed of roller to fit the deposition speed of wrapped tape by using the feeding motor.

Therefore, the roller would yaw around the winding point to measure the winding angle, without effect on the position error. And the linear grating on the cylinder could measure the winding position error precisely.

The basic structure of these systems is shown in Figure 10, where $W_{Z}$ and $W_{X}$ are the offset between $\{M\}$ and $\{W\}$, $B_{X}$ and $B_{Z}$ are the offset between $\{R\}$ and $\{B\}, x_{W}$ and $z_{W}$ are the position of roller forward-point in $\{W\}, x_{M}$ and $z_{M}$ are the position of the rotation system in $\{M\}$, and $\theta$ is the rotation angle of the roller. In the system, the position of the winding point in the work piece coordinate system and the rotation angle roller can be transformed into the position of the rotation system in the machine coordinate [14]. It could be calculated by

$$
\begin{aligned}
{ }^{M} P_{\mathrm{BORG}} & ={ }_{W}^{M} T \cdot{ }_{R} T \cdot{ }^{R} P_{\mathrm{BORG}} \\
& =\left[\begin{array}{ccc}
1 & 0 & W_{X} \\
0 & 1 & W_{Z} \\
0 & 0 & 1
\end{array}\right]\left[\begin{array}{ccc}
\cos \theta & -\sin \theta & x_{W} \\
\sin \theta & \cos \theta & z_{W} \\
0 & 0 & 1
\end{array}\right]\left[\begin{array}{c}
B_{X} \\
B_{Z} \\
1
\end{array}\right] \\
& =\left[\begin{array}{c}
x_{M} \\
z_{M} \\
1
\end{array}\right] .
\end{aligned}
$$


Here, ${ }_{W}^{M} T$ is the transformation matrix from $\{M\}$ to $\{W\}$; ${ }_{R} T$ is the transformation matrix from $\{W\}$ to $\{R\} ;{ }^{R} P_{\text {BORG }}$ is the position of rotation system in $\{R\} ;{ }^{M} P_{\mathrm{BORG}}$ is the position of rotation system in $\{M\}$.

Defining the rotation matrix as $R$, the offset between $\{R\}$ and $\{B\}$ as $B$, the offset between $\{M\}$ and $\{W\}$ as $W$, the position of roller forward-point in $\{W\}$ as ${ }^{W} P_{R}$, and the position of rotation system in $\{M\}$ as ${ }^{M} P_{B}$, (9) can be changed to

$$
R \cdot B+{ }^{W} P_{R}+W={ }^{M} P_{B} .
$$

Differentiate ${ }^{M} P_{B}$; there is

$$
\mathrm{d}^{M} P_{B}=\frac{\partial R \cdot B}{\partial \theta} \mathrm{d} \theta+\mathrm{d}^{W} P_{R} .
$$

According to (11), the speed of ${ }^{M} P_{B}$ is comprised of the speed of ${ }^{W} P_{R}$ and the angular speed of the flexible roller.

According to the analysis of principle operation for flexible roller system, the interpolate controller should have the function of calculating the feeding axis compensation value in real time based on the changing angle. In order to design the interpolation control program, the speed of ${ }^{M} P_{B}$ should be discrete. Using first-order difference quotient to discrete equation (11), there is

$$
\Delta^{M} P_{B}=R B(\theta)-R B(\theta-\Delta \theta)+\Delta^{W} P_{R} .
$$

According to (12), the interpolation increment of ${ }^{M} P_{B}$ in $n$ sampling time is shown in

$$
\Delta z_{M n}=B_{X} C_{1}-B_{Z} C_{2}+\Delta z_{W n} .
$$

Here, $C_{1}=\sin \theta_{n}-\sin \theta_{n-1} ; C_{2}=\cos \theta_{n}-\cos \theta_{n-1}$.

When a winding angle increment is detected, the calculated interpolation increment $\Delta z_{M n}$ would be transmitted to the feeding motor, and the roller would be fixed to the winding point on the feeding axis. Therefore, the roller could yaw around the winding point to measure the winding angle, and the winding position error could be acquired from the linear grating.

\section{Design of the Flexible Winding Speed Control System}

In summary, during tape winding process, error of tape thickness would cause a location error for compaction roller to wrapped layer, and there would be error of winding angle and error of winding position. According to (4), (6), and (8), it is feasible to eliminate the errors by control of the winding speed during winding process.

As noted above, the changing of winding angle is complex, parameter related, and nonlinear to the winding speed; on the other hand, winding position error is simply integral to the winding speed.

According to this, a fuzzy speed controller is used for winding angle control, and a differential controller is used for winding point position control [15].
TABLE 1: Fuzzy speed control rule.

\begin{tabular}{lccccc}
\hline si & & & e & & \\
& MB & MS & Z & S & B \\
\hline de & & & & & \\
MB & B & S & S & Z & Z \\
MS & B & S & S & Z & MS \\
Z & S & S & Z & MS & MS \\
S & S & Z & MS & MS & MB \\
B & Z & Z & MS & MS & MB \\
\hline
\end{tabular}

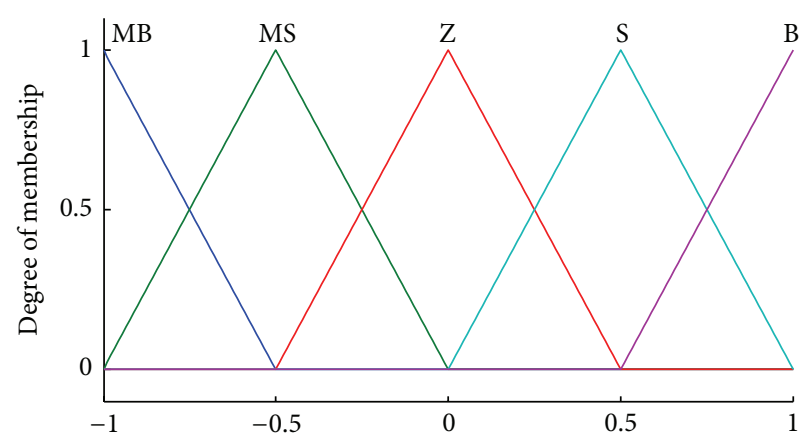

FIGURE 11: Degree of membership for inputs and output.

The fuzzy speed controller is a two-input, single-output system; the input variables are winding angle error $e(t)$ and its differential $\mathrm{d} e(t)$; the domain range corresponding to the inputs is $[0,1]$. The fuzzy speed controller output variable $s i(t)$ is the winding speed increment, and the corresponding domain range is $[0,1]$.

All input and output variables are described by five triangular membership functions, $\{\mathrm{MB}, \mathrm{MS}, \mathrm{Z}, \mathrm{S}, \mathrm{B}\}$, which means \{minus big, minus small, zero, small, big\}, shown in Figure 11 .

The fuzzy speed control rule is described in Table 1.

The relationship of inputs and output of the controller is shown by surface of the control rules as in Figure 12.

According to (6), identical winding speed for a thicker tape can be calculated as

$$
B_{n+1}=\frac{\delta+e_{\mathrm{th}}}{\sin \theta_{n}}=\tau_{n} \cot \theta_{n}+B_{n} .
$$

It is shown in (13) that the gain of differential controller could be set to $\cot \theta_{n}$.

Therefore, a double loop control system is designed for flexible winding speed control system, as shown in Figure 13.

The tape layer was accumulating during the winding process; the flexible roller system could follow the changing of winding angle and measure the winding point error in real time. With the measurement, winding speed control system regulates winding speed to adjust the errors. A fuzzy speed controller is used to adjust the winding angle error, and a differential controller is used to control the winding position error. The switch of controllers is operated by position error; if the position error was less than a threshold, the fuzzy speed controller would be activated to adjust the winding angle 


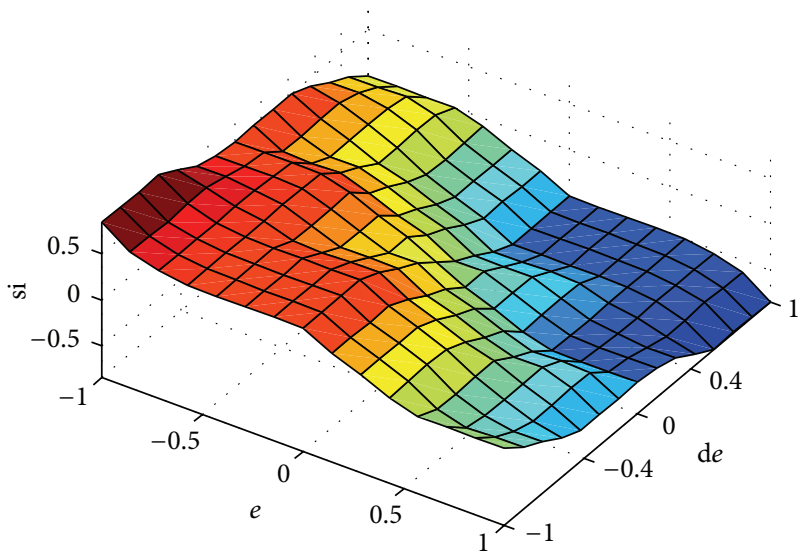

FIGURE 12: Surface of the fuzzy speed controller.

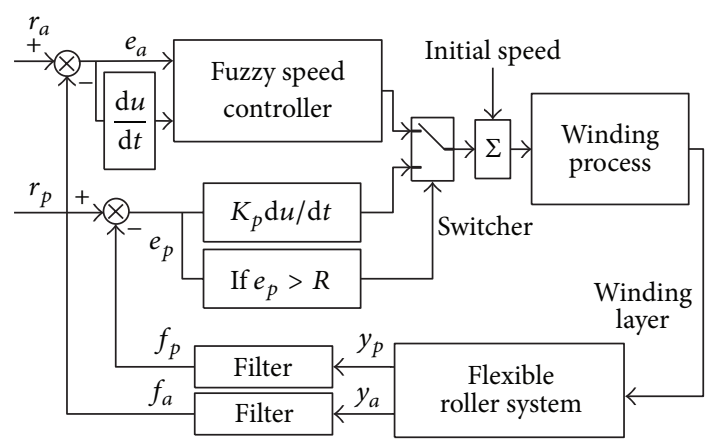

FIGURE 13: Flexible winding speed control system.

error; else, the differential controller would be activated to control the position error.

\section{Experiments and Results}

Carbon fiber prepreg tape has been used for winding cylinder mandrel in flexible winding experiment. The experiment system is shown in Figure 14.

In the experiment, the position error threshold is set to $0.5 \mathrm{~mm}$, and winding angle is $12^{\circ}$, the tape width is $40 \mathrm{~mm}$, the tape thickness is $0.2 \sim 0.24 \mathrm{~mm}$ (20 points on the tape have been measured), the mandrel rotation speed is set to 20 revolutions per minute, and $160 \mathrm{~mm}$ diameter cylinder mandrel has been used. There were two parts of the experiment as follows: speed control experiment and winding experiment.

6.1. Fuzzy Winding Speed Control Experiment. In order to test the winding speed control system, the initial winding speed is set to $1.5 \mathrm{~mm}$ per revolution, which is calculated by the thickness of $0.31 \mathrm{~mm}$, about $30 \%$ thicker than the used tape.

The winding speed of the experiment is shown in Figure 15. In the experiment, winding speed converged to $1 \mathrm{~mm}$ per revolution in 30 seconds, which was the winding speed for the tape thickness calculated by the thickness of $0.21 \mathrm{~mm}$. The maximum winding angle error is $1.1^{\circ}$, and the maximum winding position error is $0.55 \mathrm{~mm}$.

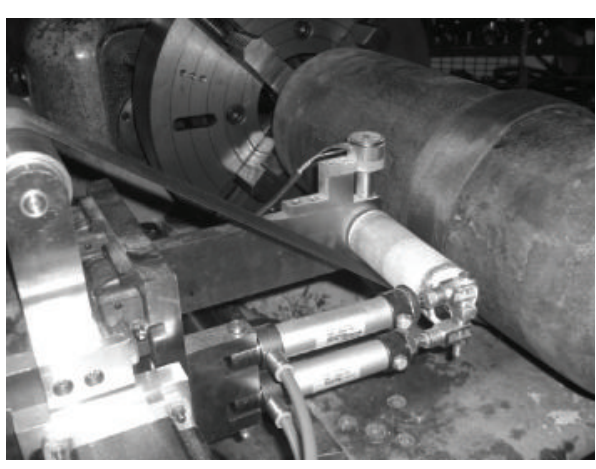

Figure 14: Flexible winding experiment system.

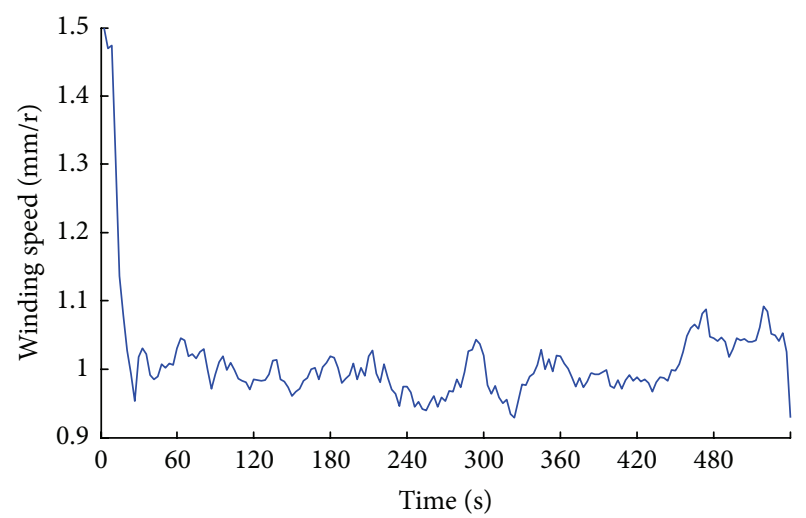

FIGURE 15: Winding speed of the experiment.

6.2. Tape Winding Experiment. Three groups in tape winding experiment have been finished as follows: control group, standard winding group, and flexible winding group.

In order to calculate the porosity of winding product, a reference product has been cured for 120 minutes at $0.5 \mathrm{Mpa}$ and $150^{\circ} \mathrm{C}$ in the control group; the porosity could be calculated as

$$
P=\left(1-\frac{\rho_{0}}{\rho}\right) \times 100 \% .
$$

Here, $P$ is the porosity of the winding product; $\rho_{0}$ is density of the winding product; $\rho$ is the density of the reference product.

Curing process of control group is shown in Figure 16, and reference product of control group is shown in Figure 17.

The size of the product of control group is $4.4 \mathrm{~mm}$ high, $40 \mathrm{~mm}$ wide, and $47 \mathrm{~mm}$ long, and the mass is $3.2 \mathrm{~g}$, and the density is $1.596 \mathrm{~g} / \mathrm{cm}^{3}$.

The flexible winding group of experiment is shown in Figure 18.

The winding products have been cured with vacuum assist for 120 minutes at $150^{\circ} \mathrm{C}$. A flexible winding product is shown in Figure 19.

The section of the standard winding product is shown in Figure 20. The black part in the figure is the pore in product. The density of the product is $1.492 \mathrm{~g} / \mathrm{cm}^{3}$; according to 


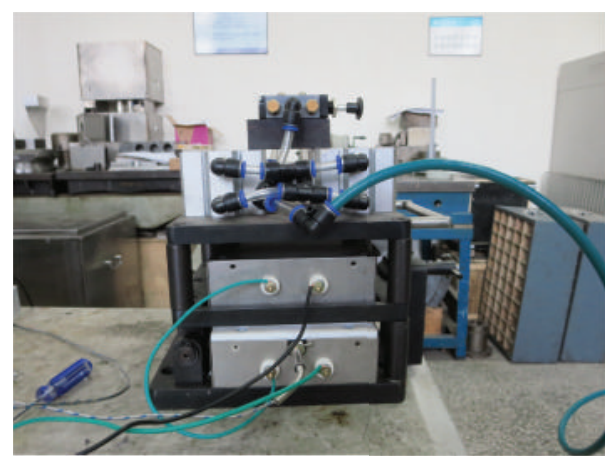

FIGURE 16: Curing process of control group.

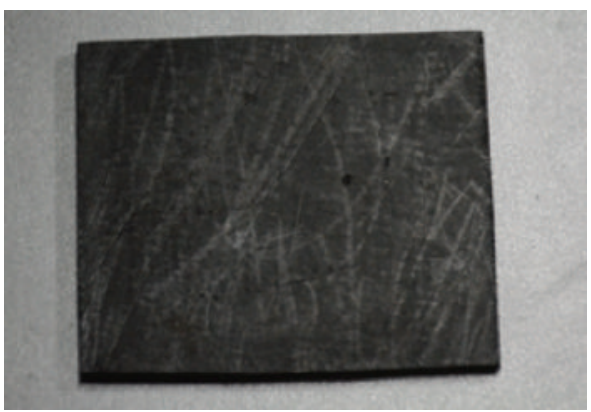

FIGURE 17: Reference product.

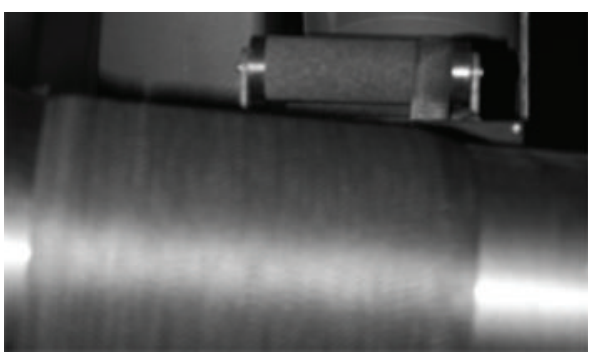

FIgURE 18: Flexible winding experiment.

the reference product, the porosity of the standard winding product is $6.5 \%$.

The inner surface of the standard winding product is shown in Figure 21. The dark part marked by red line is the flaw when a thicker tape had been used during tape winding, as analyzed in Figure 7.

The section of the flexible winding product is shown in Figure 22 and the density of the product is $1.586 \mathrm{~g} / \mathrm{cm}^{3}$; according to the reference product, the porosity of flexible winding product is $0.6 \%$.

The inner surface of the flexible winding product is shown in Figure 23. Compared to the standard winding product, a smooth inner surface has been finished with flexible winding system.

\section{Conclusions}

In order to eliminate the winding errors such as winding angle error and winding position error caused by tape

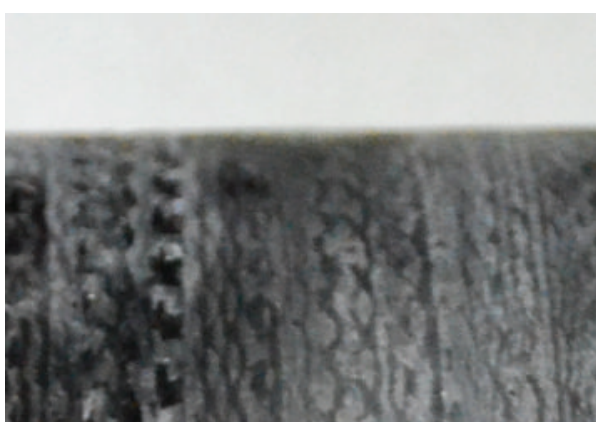

FIGURE 19: Flexible winding product.

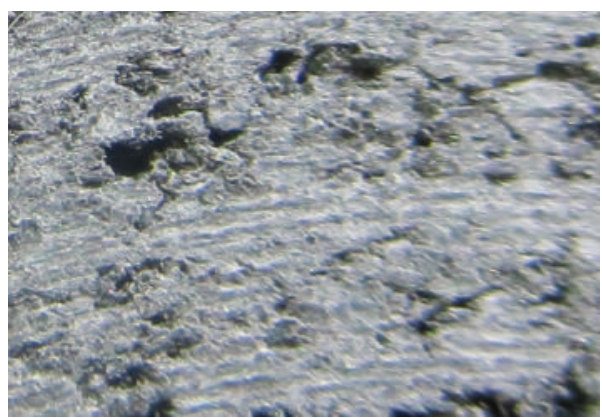

FIGURE 20: Section of standard winding product.

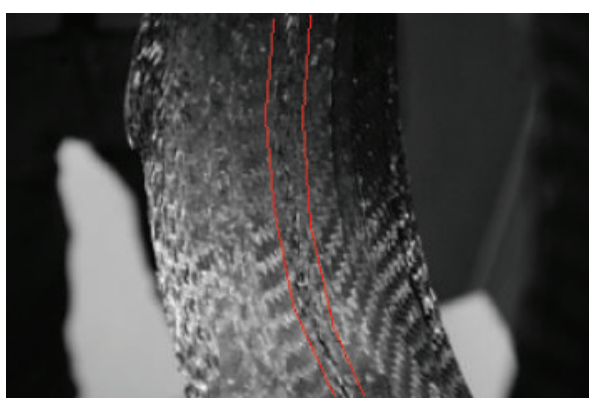

FIGURE 21: Inner surface of standard winding product.

thickness error and other factors during composite tape winding process, a novel flexible winding system has been presented and tested. Design requirement and working principle have been analyzed in detail; the key factors of the flexible winding system have been found. These results laid the foundation for establishing the system.

According to the control factors, a flexible roller system and a winding speed controller have been established. Flexible winding experiment has been done for fiber prepreg tape. The flexible winding system has been proved to be feasible. It has been realized that the flexible winding system could adjust the winding speed to fit the thickness error of the resin prepreg tape. According to the experiment result, a thickness error which is about $30 \%$ thicker than the used tape can be convergent in 30 seconds; the maximum winding angle error is controlled in $1.1^{\circ}$, and the maximum winding position error is controlled in $0.55 \mathrm{~mm}$; compared to the standard winding 


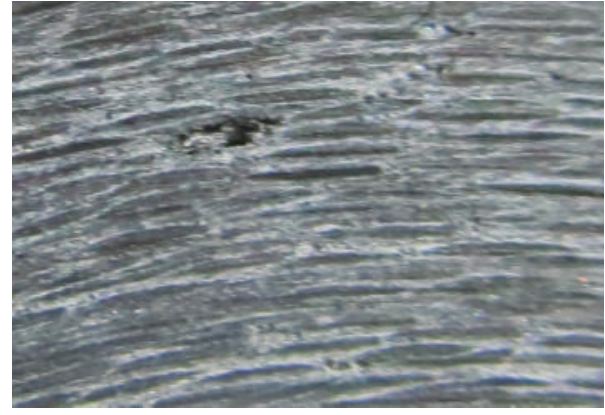

FIGURE 22: Section of flexible winding product.

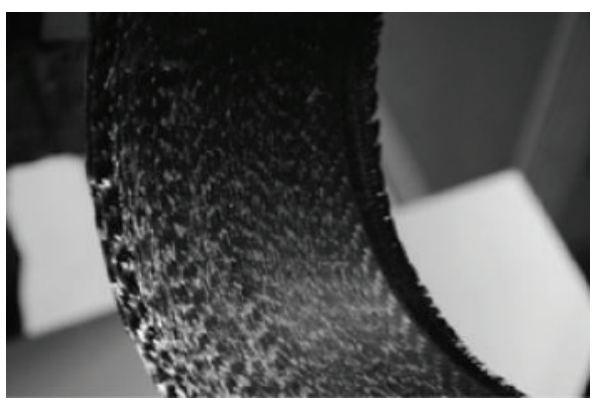

FIGURE 23: Inner surface of flexible winding product.

product, the porosity of flexible winding product could be improved from $6.5 \%$ to $0.6 \%$ and a smooth surface could be achieved in flexible winding product. An accuracy tape winding process could be guaranteed by using the flexible winding system.

\section{Conflict of Interests}

The authors declare that there is no conflict of interests regarding the publication of this paper.

\section{References}

[1] A. Canfield, R. G. Clinton, W. Armour, and J. Koenig, "Improved ablative materials for the ASRM nozzle," Tech. Rep., 1992.

[2] S. K. Mazumdar, Automated manufacturing of composite components by thermoplastic tape winding and filament winding [Doctoral dissertation], Concordia University, 1994.

[3] H. J. Kim, S. K. Kim, and W. I. Lee, "A study on heat transfer during thermoplastic composite tape lay-up process," Experimental Thermal and Fluid Science, vol. 13, no. 4, pp. 408-418, 1996.

[4] A. Littlefield, E. Hyland, A. Andalora, N. Klein, R. Langone, and R. Becker, "Carbon fiber/thermoplastic overwrapped gun tube," Journal of Pressure Vessel Technology, vol. 128, no. 2, pp. 257-262, 2006.

[5] C. D. Rudd, M. R. Turner, A. C. Long, and V. Middleton, "Tow placement studies for liquid composite moulding," Composites Part A: Applied Science and Manufacturing, vol. 30, no. 9, pp. 1105-1121, 1999.
[6] N. Hassan, J. E. Thompson, R. C. Batra, A. B. Hulcher, X. Song, and A. C. Loos, "A heat transfer analysis of the fiber placement composite manufacturing process," Journal of Reinforced Plastics and Composites, vol. 24, no. 8, pp. 869-888, 2005.

[7] T. Aized and B. Shirinzadeh, "Robotic fiber placement process analysis and optimization using response surface method," The International Journal of Advanced Manufacturing Technology, vol. 55, no. 1-4, pp. 393-404, 2011.

[8] M. L. Costa, S. F. M. De Almeida, and M. C. Rezende, “The influence of porosity on the interlaminar shear strength of carbon/ epoxy and carbon/bismaleimide fabric laminates," Composites Science and Technology, vol. 61, no. 14, pp. 2101-2108, 2001.

[9] B. Madsen and H. Lilholt, "Physical and mechanical properties of unidirectional plant fibre composites-an evaluation of the influence of porosity," Composites Science and Technology, vol. 63, no. 9, pp. 1265-1272, 2003.

[10] H. Koushyar, S. Alavi-Soltani, B. Minaie, and M. Violette, "Effects of variation in autoclave pressure, temperature, and vacuum-application time on porosity and mechanical properties of a carbon fiber/epoxy composite," Journal of Composite Materials, vol. 46, no. 16, pp. 1985-2004, 2012.

[11] Y. Y. Shi, H. Tang, and Q. Yu, "Key technology of the NC tape winding machine," Acta Aeronautica et Astronautica Sinica, vol. 29, no. 1, pp. 233-239, 2008.

[12] E. J. Wernimont, "48-inch subscale motor material testing of Space Shuttle Advanced Solid Rocket Motor nozzle carbon cloth phenolic ablatives," in Proceedings of the 29th Joint Propulsion Conference and Exhibit, AIAA-93-2213, June 1993.

[13] S. C. Mantell and G. S. Springer, "Manufacturing process models for thermoplastic composites," Journal of Composite Materials, vol. 26, no. 16, pp. 2348-2377, 1992.

[14] S. B. Niku, Introduction to Robotics: Analysis, Systems, Applications, vol. 7, Prentice Hall, New Jersey, NJ, USA, 2001.

[15] O. Karasakal, M. Guzelkaya, I. Eksin, and E. Yesil, "An errorbased on-line rule weight adjustment method for fuzzy PID controllers," Expert Systems with Applications, vol. 38, no. 8, pp. 10124-10132, 2011. 

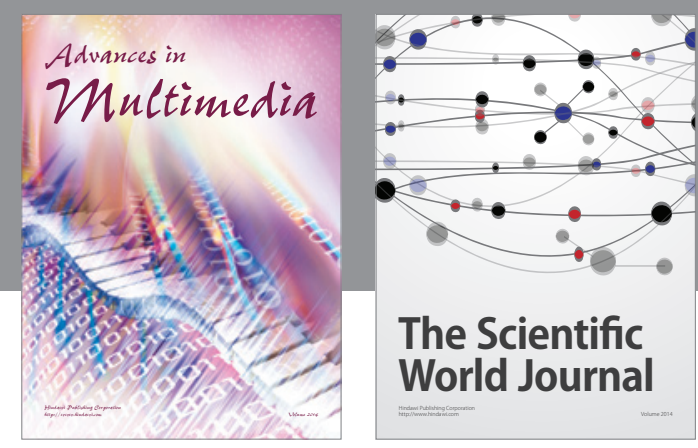

The Scientific World Journal
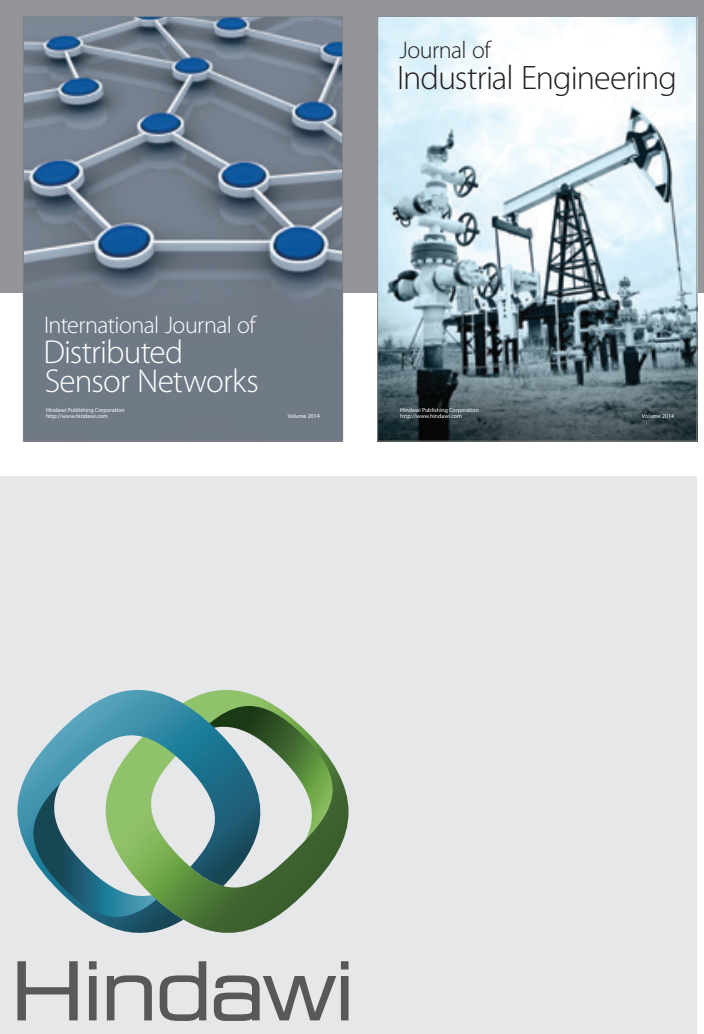

Submit your manuscripts at

http://www.hindawi.com

\section{Computer Networks} and Communications
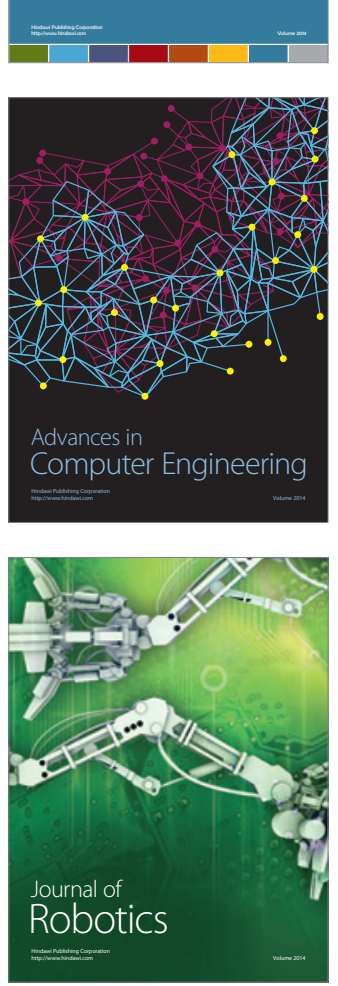
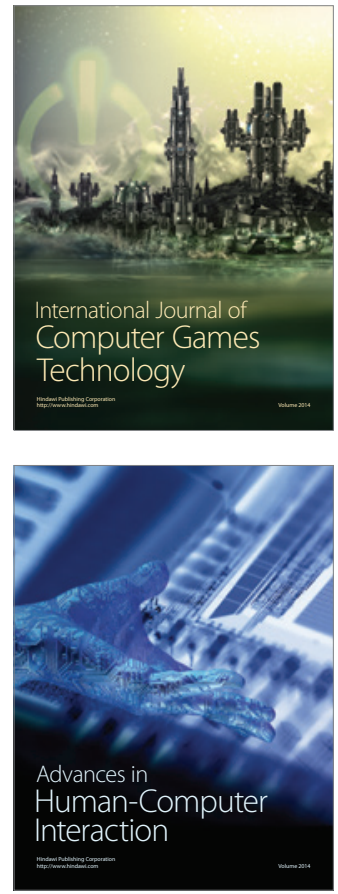
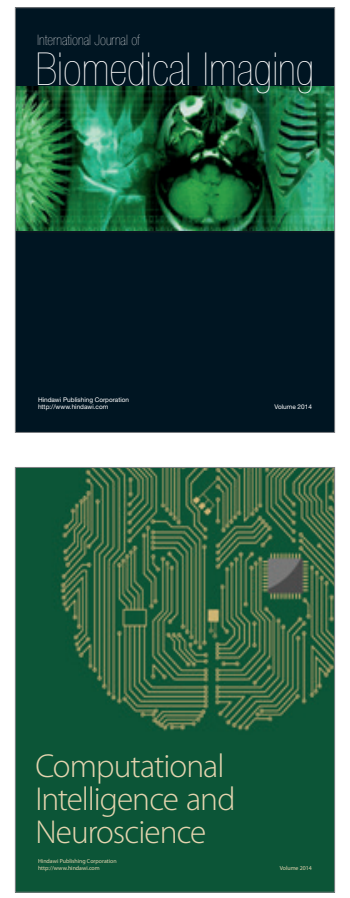
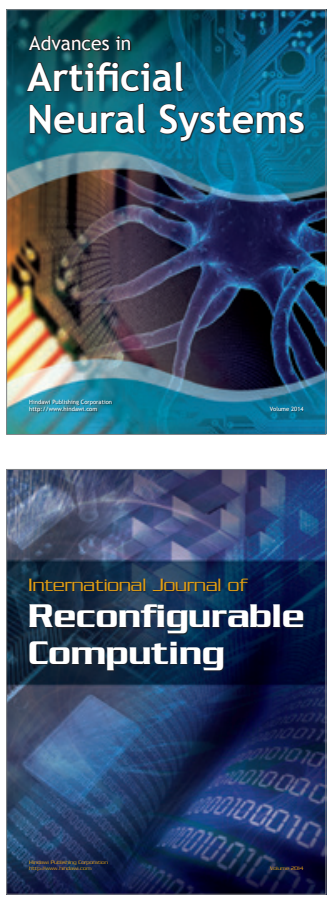
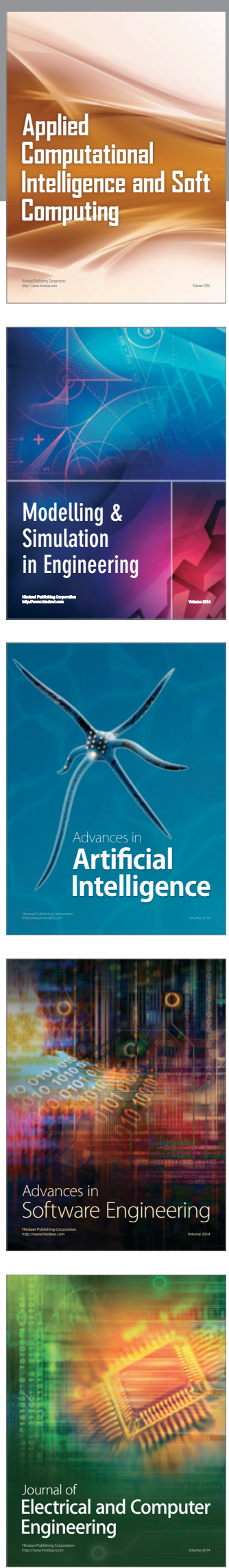